\title{
CATHARE Multi-1D Modeling of Coolant Mixing in VVER-1000 for RIA Analysis
}

\author{
I. Spasov, ${ }^{1}$ J. Donov, ${ }^{1}$ N. P. Kolev, ${ }^{1}$ and L. Sabotinov ${ }^{2}$ \\ ${ }^{1}$ Institute for Nuclear Research and Nuclear Energy, Tsarigradsko Chaussee 72, 1784 Sofia, Bulgaria \\ ${ }^{2}$ Institute de Radioprotection et Surete Nucleaire, 92262 Fontenay-aux-Roses, France \\ Correspondence should be addressed to N. P. Kolev, npkolev@abv.bg
}

Received 25 April 2009; Accepted 25 October 2009

Academic Editor: Alessandro Petruzzi

Copyright (C) 2010 I. Spasov et al. This is an open access article distributed under the Creative Commons Attribution License, which permits unrestricted use, distribution, and reproduction in any medium, provided the original work is properly cited.

\begin{abstract}
The paper presents validation results for multichannel vessel thermal-hydraulic models in CATHARE used in coupled 3D neutronic/thermal hydraulic calculations. The mixing is modeled with cross flows governed by local pressure drops. The test cases are from the OECD VVER-1000 coolant transient benchmark (V1000CT) and include asymmetric vessel flow transients and main steam line break (MSLB) transients. Plant data from flow mixing experiments are available for comparison. Sufficient mesh refinement with up to 24 sectors in the vessel is considered for acceptable resolution. The results demonstrate the applicability of such validated thermal-hydraulic models to MSLB scenarios involving thermal mixing, azimuthal flow rotation, and primary pump trip. An acceptable trade-off between accuracy and computational efficiency can be obtained.
\end{abstract}

\section{Introduction}

This work is motivated by the need for improved singlephase vessel mixing models in system codes that are able to properly represent local effects in reactivity insertion accidents. The study has been performed in Phase 2 of the OECD VVER-1000 coolant transient benchmarks labelled V1000CT-2 [1, 2]. These benchmarks provide a consistent approach to the testing of coupled neutronic/thermalhydraulic codes. Separate exercises are devoted to standalone testing of thermal hydraulic and core physics models. Then the validated models are tested in coupled code simulation of asymmetric MSLB transients.

The V1000CT-2 vessel mixing benchmark [1] is based on a steam generator isolation experiment during the plant commissioning phase of Kozloduy-6 in Bulgaria. Local and integral plant data are available for comparison. The objective of this benchmark is to test the capability of system and CFD codes to represent in-vessel thermal hydraulics. The purpose of the V1000CT-2 MSLB benchmark is to test the core neutronics and coupled N/TH calculations. This paper presents results of thermal-hydraulic calculations with CATHARE [3] for the VVER-1000 coolant mixing and MSLB benchmarks.

\section{The VVER-1000 Reactor}

The reference plant is Kozloduy-6 with a VVER-1000 V320 in Bulgaria. This is a four-loop pressurized water reactor with horizontal steam generators (SGs). The steam is supplied to a $1000 \mathrm{MWe}$ turbine. The core is of open type and contains 163 hexagonal fuel assemblies, each of which has 312 fuel rods, 18 guide channels for control rods, and a central instrumentation tube. The fuel pins are arranged in triangular grid. The geometry of the reactor pressure vessel is shown in Figure 1. See [1] for details.

The flow in the lower part of the vessel is throttled through the perforated barrel bottom (1344 holes) and the perforated fuel support columns serving as flow distributors. The support columns are welded at the core support plate so that no flow passes around the support columns. The primary coolant flows through the slots, upward through the support columns, and into the fuel assemblies. The flow through the core region consists of flow through the heated part and $2.9 \%$ bypass flow of which $2.2 \%$ is through the control rod guide channels and water holes.

At the upper core plate most of the fuel assembly heads are connected to guide tubes located in the upper plenum to protect the control rods and instrumentation 


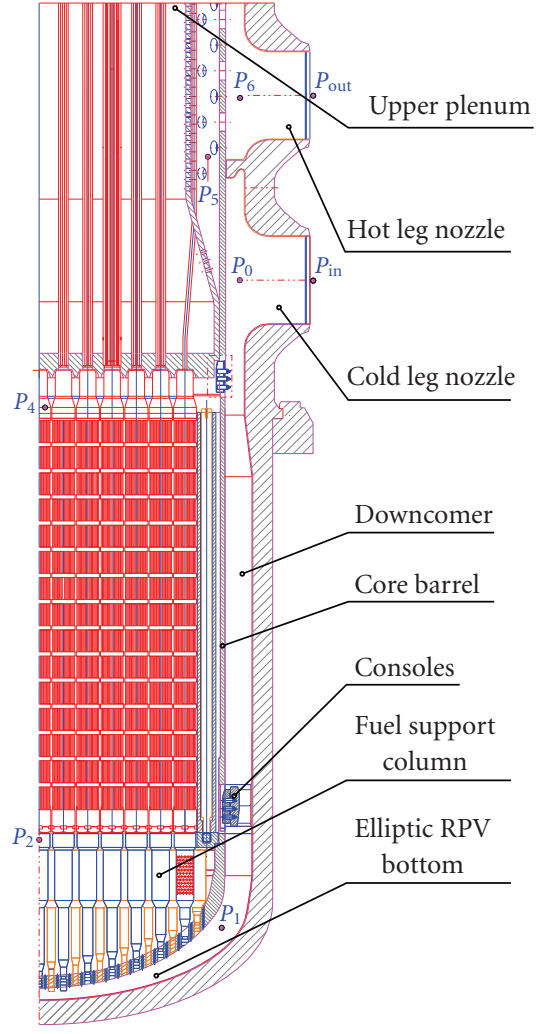

FIGURE 1: VVER-1000 reactor pressure vessel and internals.

cables from mechanical impacts. The bulk flow to the upper plenum passes mainly through the holes of the upper plate around the guide tubes. The bypass flow through the guide tubes is about $1 \%$ of the total because of the small flow area of the available orifices (see [1]). The outlets of ninety five assemblies are equipped with thermocouples located eccentrically in the upper part of the assembly head. Because of construction peculiarities there is a quasistagnation flow at the location of the thermocouples. The cooler jets through the control rod guide channels cause the measured temperature to be somewhat lower than the real coolant temperature at the end of the heated part. This should be taken into account when comparing with computations, or estimated core inlet temperatures can be used for comparison.

The flow in the upper plenum passes upwards, then through the perforated walls of the support ring and the core barrel to the vessel outlet.

\section{Test Cases}

3.1. Calculation of the Kozloduy-6 Vessel Mixing Experiment. The Kozloduy-6 SG isolation problem at 9.36\% nominal power and the corresponding vessel mixing was chosen as reference problem of the OECD V1000CT-2 Benchmark, Exercise 1 [1]. The benchmark provides a validation test of the vessel thermal hydraulics in case of loop temperature and flow disturbances with all main coolant pumps (MCPs) in operation. It is relevant to the initial part of VVER-1000 MSLB scenarios from hot full power. The test problem is considered as pure thermal hydraulic problem because the moderator temperature reactivity coefficient was close to zero and the relative power distribution was approximately constant during the transient.

The mixing experiment was initiated by disturbing loop no. 1. It includes three states: a stabilized initial state, a transient state, and a stabilized final state. These states are briefly described below. After the stabilization of the core outlet temperature and the pressure, the experiment was repeated for loop no. 2. The transient caused by disturbing loop no. 1 is selected for the coolant mixing analysis and the data of the second experiment is used indirectly to support the analysis.

3.1.1. Initial State. The reactor is at the beginning of Cycle 1 and the power is $9.36 \%$ of the nominal. All four MCPs and four SGs are in operation. The pressure above the core is $15.59 \mathrm{MPa}$, close to the nominal value of $15.7 \mathrm{MPa}$. The coolant temperature at the reactor inlet is $268.6^{\circ} \mathrm{C}$ and the boron acid concentration is $7.2 \mathrm{~g} / \mathrm{kg}$ (the coolant temperature reactivity coefficient is zero near $7.5 \mathrm{~g} / \mathrm{kg}$ ). For this initial state, the fuel assembly temperature rise $\delta \mathrm{T}_{k, \text { rel }} k$ $=1,95$ in 95 instrumented assemblies was calculated from measured cold leg and assembly outlet temperatures. The measured data and the 60-degree rotational symmetry of the fresh fuel core were used to estimate the heat up for assemblies without temperature control, so that the full core temperature rise distribution was obtained.

3.1.2. Transient. A transient was initiated by closing the steam isolation valve of SG-1 and isolating SG-1 from feed water. The pressure in SG-1 started to increase and stabilized at $6.47 \mathrm{MPa}$ in about 20 minutes. The main steam header pressure was maintained approximately constant during the transient by operating the steam dump to condenser in pressure control mode. The coolant temperature in the cold and hot legs of loop no. 1 rose by approximately $13.5^{\circ} \mathrm{C}$ and the mass flow rate decreased by about $3.4 \%$. The mass flow rate through the reactor decreased by about $1 \%$. At 90 seconds after the disturbance, the temperature of cold leg no. 1 exceeded that of the hot leg. The difference stabilized to $0.6-0.8^{\circ} \mathrm{C}$ in about 20 minutes. The reactor power changed $0.16 \%$ calculated from primary circuit energy balance. The initially symmetric core power distribution did not change significantly.

3.1.3. Final State. For the analysis presented here, the stabilized state of the experiment 30 minutes after the separation of the SG-1 is considered as "final state." The core inlet temperatures were calculated from the measured core outlet temperatures and the estimated assembly by assembly temperature rise $\delta \mathrm{T}_{k}, k=1,163$ for the initial state, where $k$ is the assembly number. The $\delta \mathrm{T}_{k \text {,rel }}$ distribution was assumed constant during the transient due to the approximately constant normalized core power distribution. 


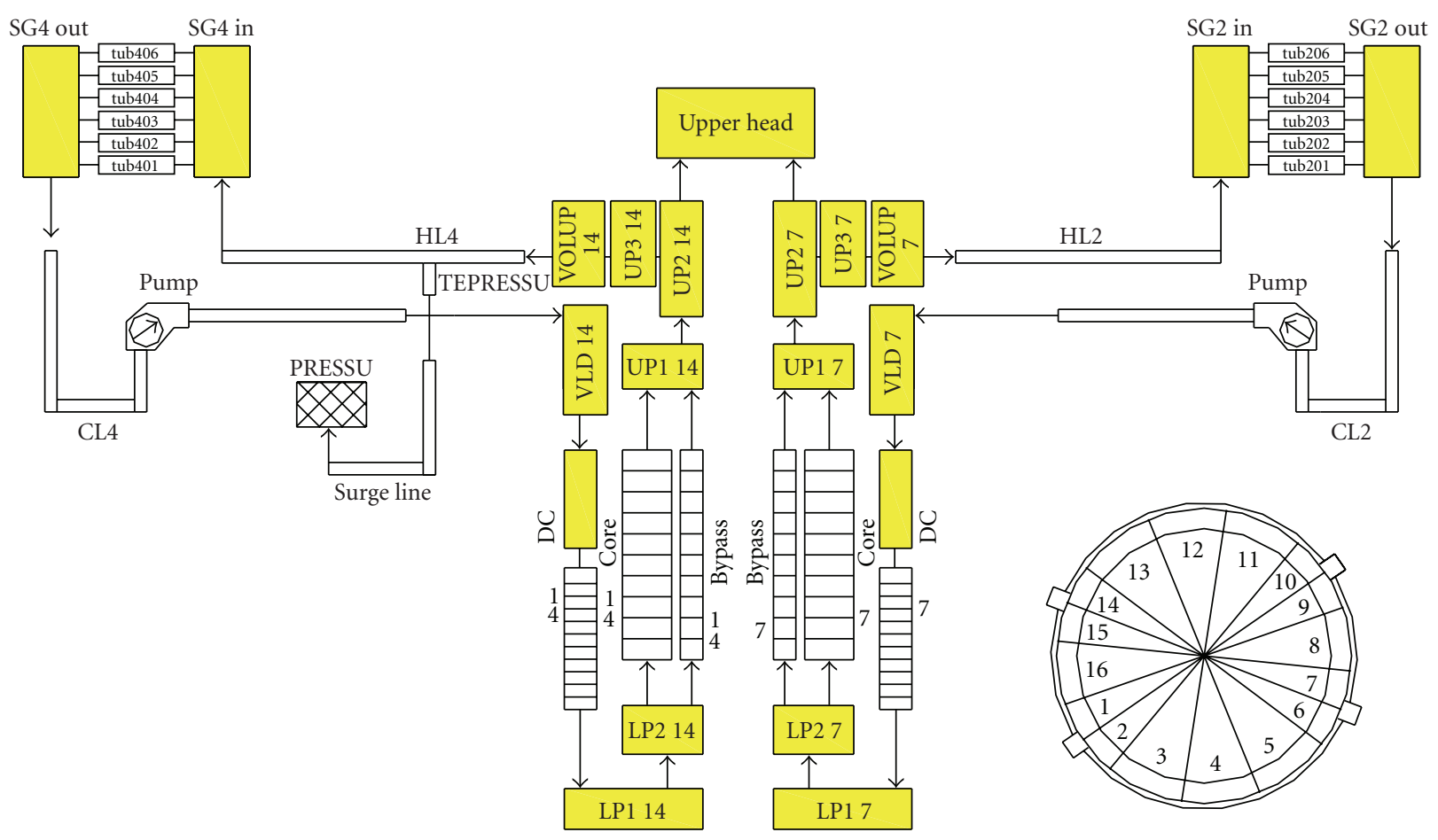

\footnotetext{
Volume

$\square$ Axial element

$\otimes$ BC
}

FIgURE 2: Primary circuit nodalization scheme (2 of 16 vessel channels are shown).

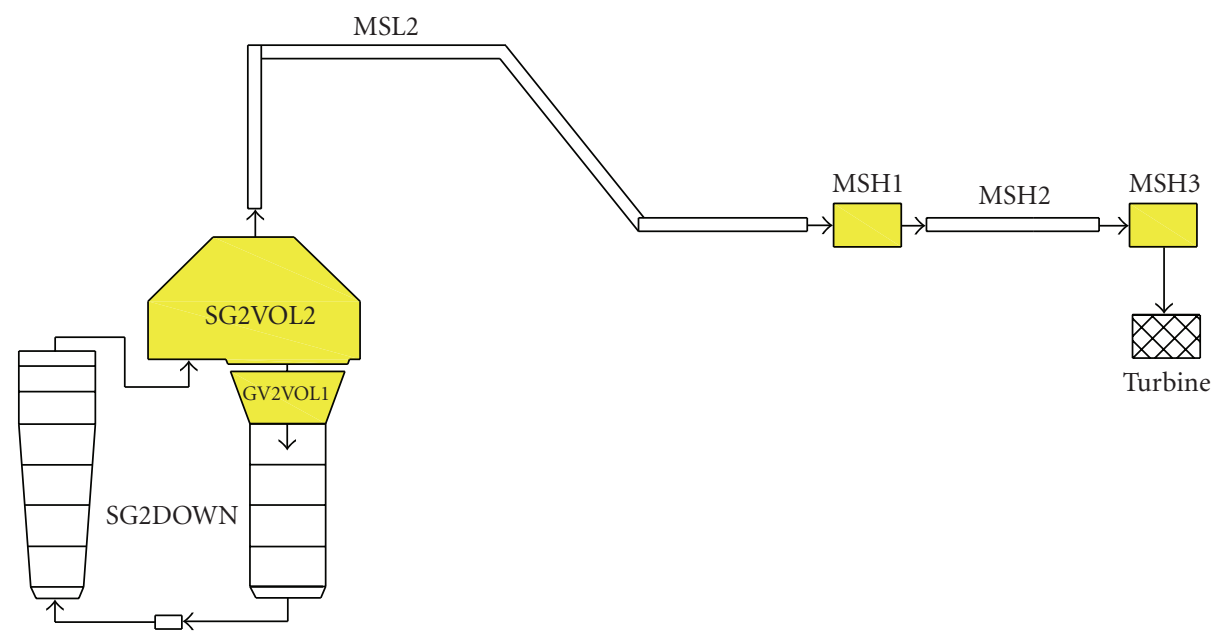

Volume

Axial element

$\mathbb{B C}$

FIGURE 3: Secondary circuit nodalization scheme (SG-2 and steam line 2 are shown). 
TABLE 1: Initial state.

\begin{tabular}{|c|c|c|c|c|c|}
\hline Parameter & Plant data & Cathare 12 sectors & Cathare 16 sectors & Cathare 24 sectors & Uncertainty \\
\hline Core power, MW & 281 & 281 & 281 & 281 & \pm 60 \\
\hline Pressure above the core, $\mathrm{MPa}$ & 15.59 & 15.608 & 15.605 & 15.605 & \pm 0.3 \\
\hline Cold leg no. 1 coolant temp, $\mathrm{K}$ & 541.75 & $541.75(\mathrm{BC})$ & $541.75(\mathrm{BC})$ & $541.75(\mathrm{BC})$ & \pm 1.5 \\
\hline Cold leg no. 2 coolant temp, $\mathrm{K}$ & 541.85 & $541.85(\mathrm{BC})$ & $541.85(\mathrm{BC})$ & $541.85(\mathrm{BC})$ & \pm 1.5 \\
\hline Cold leg no. 3 coolant temp, K & 541.75 & $541.75(\mathrm{BC})$ & $541.75(\mathrm{BC})$ & $541.75(\mathrm{BC})$ & \pm 1.5 \\
\hline Cold leg no. 4 coolant temp, $\mathrm{K}$ & 541.75 & $541.75(\mathrm{BC})$ & $541.75(\mathrm{BC})$ & $541.75(\mathrm{BC})$ & \pm 1.5 \\
\hline Mass flow rate $1, \mathrm{~kg} / \mathrm{s}$ & 4737 & 4737 & 4737 & 4737 & \pm 200 \\
\hline Mass flow rate $2, \mathrm{~kg} / \mathrm{s}$ & 4718 & 4717.9 & 4718 & 4718 & \pm 200 \\
\hline Mass flow rate $3, \mathrm{~kg} / \mathrm{s}$ & 4682 & 4682 & 4682 & 4682 & \pm 200 \\
\hline Mass flow rate $4, \mathrm{~kg} / \mathrm{s}$ & 4834 & 4834 & 4833.8 & 4833.9 & \pm 200 \\
\hline Reactor mass flow rate, $\mathrm{kg} / \mathrm{s}$ & 18971 & 18971 & 18971 & 18971 & \pm 800 \\
\hline Hot leg no. 1 coolant temp, $\mathrm{K}$ & 545 & 544.76 & 544.66 & 544.65 & \pm 1.5 \\
\hline Hot leg no. 2 coolant temp, $\mathrm{K}$ & 545.9 & 544.70 & 544.68 & 544.68 & \pm 1.5 \\
\hline Hot leg no. 3 coolant temp, K & 544.9 & 544.71 & 544.70 & 544.71 & \pm 1.5 \\
\hline Hot leg no. 4 coolant temp, K & 545 & 544.84 & 544.84 & 544.83 & \pm 1.5 \\
\hline Reactor pressure drop, $\mathrm{MPa}$ & 0.418 & 0.417 & 0.418 & 0.418 & \pm 0.043 \\
\hline
\end{tabular}

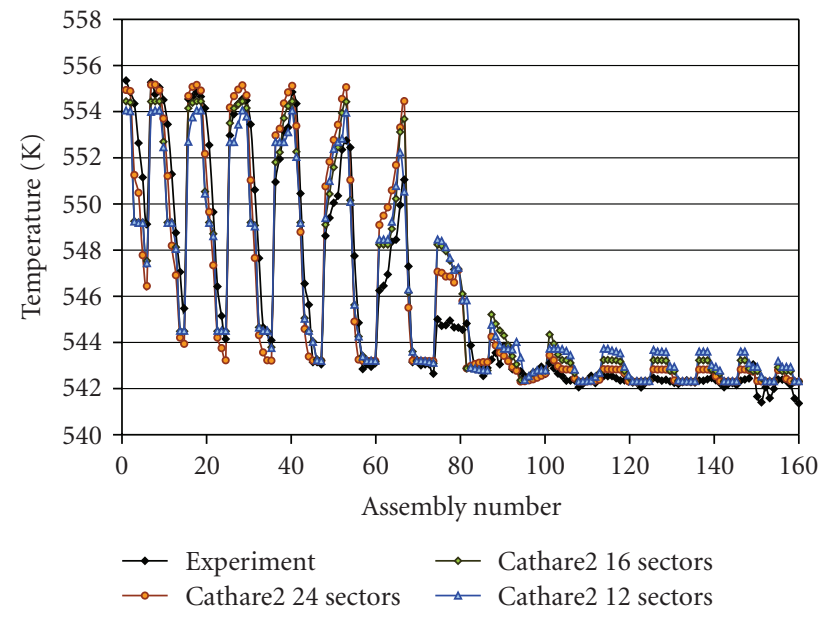

FIGURE 4: Kozloduy-6 flow mixing test: assembly by assembly core inlet temperatures.

For this analysis the benchmark problem was run with vessel boundary conditions from the V1000CT-2 benchmark specifications. The task is to calculate the coolant parameters at fuel assembly inlets and at the reactor outlets. Measured hot leg temperatures and estimated assembly inlet temperatures were used as reference.

3.2. VVER-1000 MSLB Problem. Two scenarios are defined for the purposes of OECD V1000CT-2 benchmark [2]. The first is close to the current licensing practice while the second is a pessimistic scenario derived from Scenario 1 by assuming that all main coolant pumps remain in operation and the scram worth is reduced through adjustment of the cross sections.

3.2.1. MSLB Scenario 1. Large MSLB between the SG and the steam isolation valve (SIV) without loss of off-site power.

The analysed transient is initiated by a main steam line break in a VVER-1000 between the SG and SIV, outside the containment.

One of the major concerns for this case is the possible return to power and criticality after reactor scram due to overcooling. Because of this concern, the main objective of the study is to clarify the local 3D feedback effects depending on the vessel mixing.

A burnt fuel loading with three-year fuel assemblies is considered. The reactor is at the end of cycle (EOC) and the initial hot full power (HFP) conditions are chosen consistent with the above objective. The SG water inventory is about the possible maximum at HFP. Following the break and the scram signal, one of the most reactive peripheral control assemblies remains stuck out of the core and is assumed to be in the affected sector.

A mechanical failure of the large feed water regulating valve in the broken line is assumed. At the time of the steam line rupture the valve starts to open from about $70 \%$ to $100 \%$ and then remains stuck in the open position. The main feed water flow to the faulted SG is terminated by closure of the feed water block valve in 52 seconds. The mass of feed water in the piping between the isolation valve and the affected SG, estimated to about $8000 \mathrm{~kg}$, also contributes to the overcooling. 


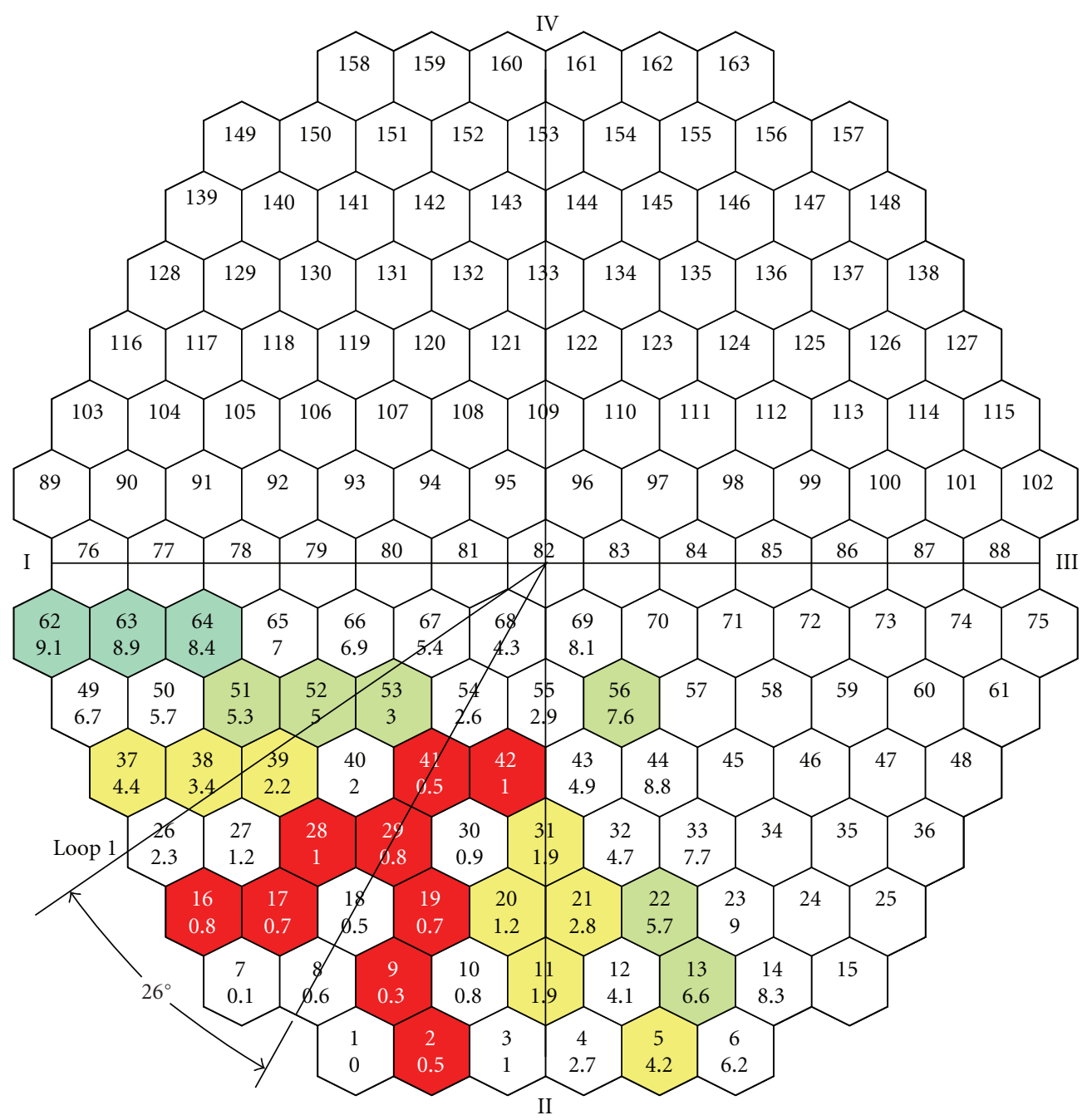

Figure 5: Plant data: estimated temperature differences (K) from cold leg no. 1 to the assembly inlets and angular turn of the loop no. 1 flow centre.

For benchmark purposes the feed-water temperature is conservatively fixed to $160^{\circ} \mathrm{C}$ to the broken SG and $170^{\circ} \mathrm{C}$ to the intact ones. In case of high-pressure safety injection operation no credit is taken for the negative reactivity insertion from the boron addition. Other major assumptions are that off-site electric power is available, and the MCPs of the faulted loop trips and the other MCP run normally during the transient.

3.2.2. MSLB Scenario 2. Large MSLB upstream of SIV without loss of off-site power and with all MCP in operation.

This is a pessimistic case derived from Scenario 1 by assuming that the MCP in the faulted loop fails to trip on signal and all reactor coolant pumps remain in operation. The scram worth is additionally reduced through adjustment of the cross sections.

For the present analysis, Exercise 2 was considered which consists of separate core-vessel calculation with given precalculated vessel MSLB boundary conditions. The reported results were obtained with validated multichannel vessel models and point kinetics.

\section{Cathare2 VVER-1000 Model}

The considered vessel thermal-hydraulic model [4-6] is multi-1D with cross-flow. For the purposes of this analysis the RPV thermal-hydraulics is described by 12-, 16-, or 24sector vessel models. The testing includes separate effects (from vessel inlet to the fuel assembly inlets), component scale (vessel with boundary conditions), and full system simulation. The main features of the TH model are summarized as follows.

\subsection{Cathare Nodalization Scheme. We have the following}

(i) multi-1D channel vessel model with $N$ sectors $(N=$ 12,16 , or 24) all the way from the inlet to the outlet. each sector is one main channel, and there is no radial subdivision, 


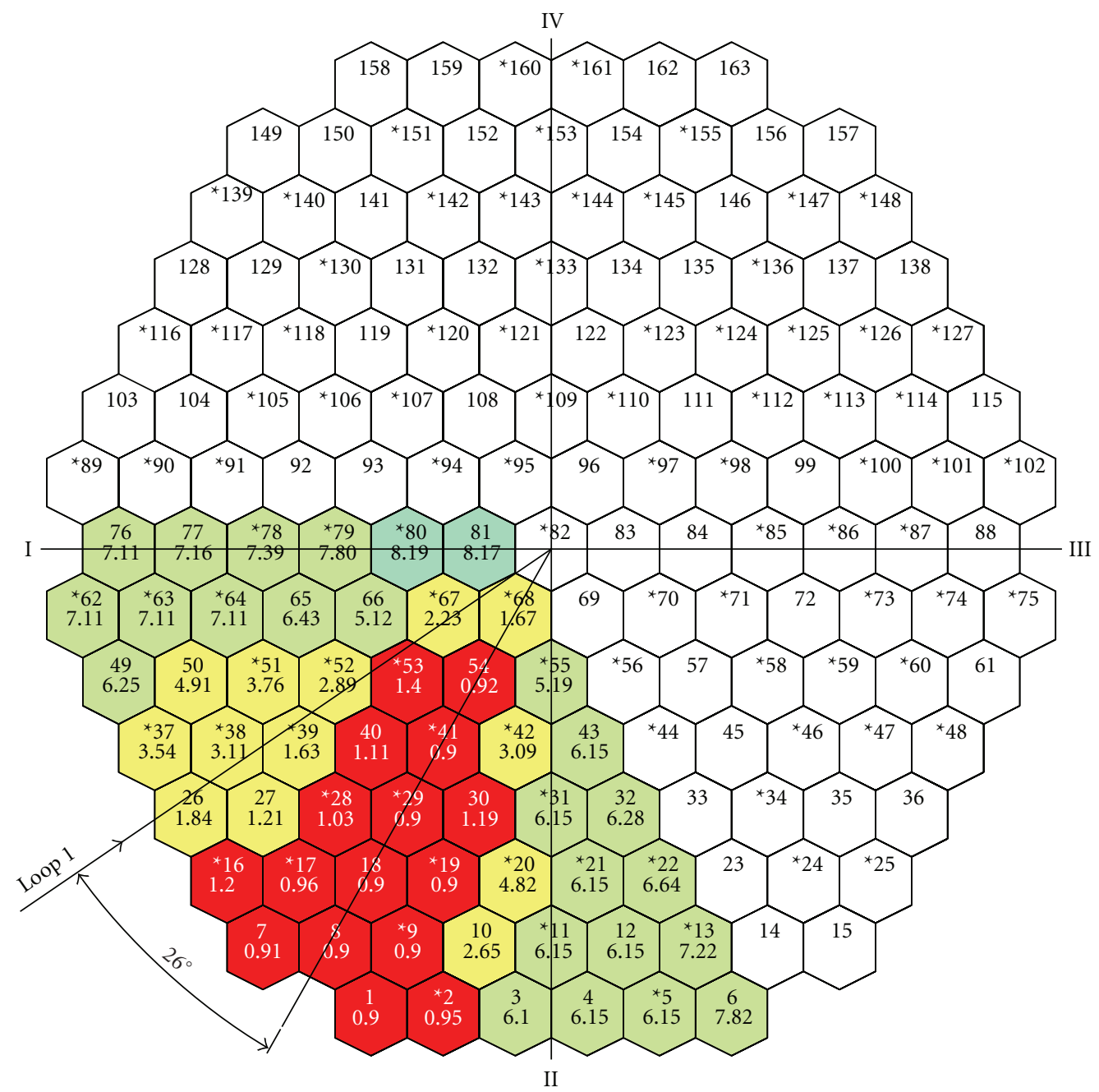

Figure 6: CATHARE 16-sector vessel model: angular turn of the loop no. 1 flow centre.

(ii) vessel inlet zone modeled with $N$ volumes,

(iii) down-comer modelled with $N \times 2$ volumes and $\mathrm{N}$ axial elements,

(iv) lower plenum modeled with 2 layers $\times N$ volumes,

(v) core with $N$ main and $N$ bypass channels,

(vi) ten axial nodes in the core,

(vii) upper plenum (shielding tubes zone) with 2 layers $\times N$ volumes,

(viii) upper plenum (annular zone) with $N$ volumes,

(ix) upper plenum (outlet zone) with $N$ volumes,

(x) upper head modelled with one volume,

(xi) four-loop system model,

(xii) SG tube bundle primary side modelled with 6 layers and 10 axial nodes,

(xiii) one-volume pressurizer model, (xiv) steam generator (SG) secondary side modelled with an axial component both for the down-comer and riser and two volumes for the upper part of the vessel,

(xv) four main steam lines connected through the main steam header.

The elements of the pressure vessel and primary circuit models are schematically shown on Figures 2 and 3.

4.2. Vessel Mixing Model. The vessel mixing is modelled through cross-flow between the parallel channels and is governed by local pressure drops. Cross-flow is modelled with horizontal junctions and vertical (diagonal) junctions connecting donor cells at a given elevation to receptor cells in the neighbour sectors, at a higher elevation. The model is implemented by the user using the utilities of the code through the input file. Tuning was applied only in the initial steady state, through adjustment of the flow resistance in horizontal cross-flow junctions and the flow area in diagonal junctions. Horizontal junctions were specified in the vessel inlet ring and in the upper part of the down-comer below 


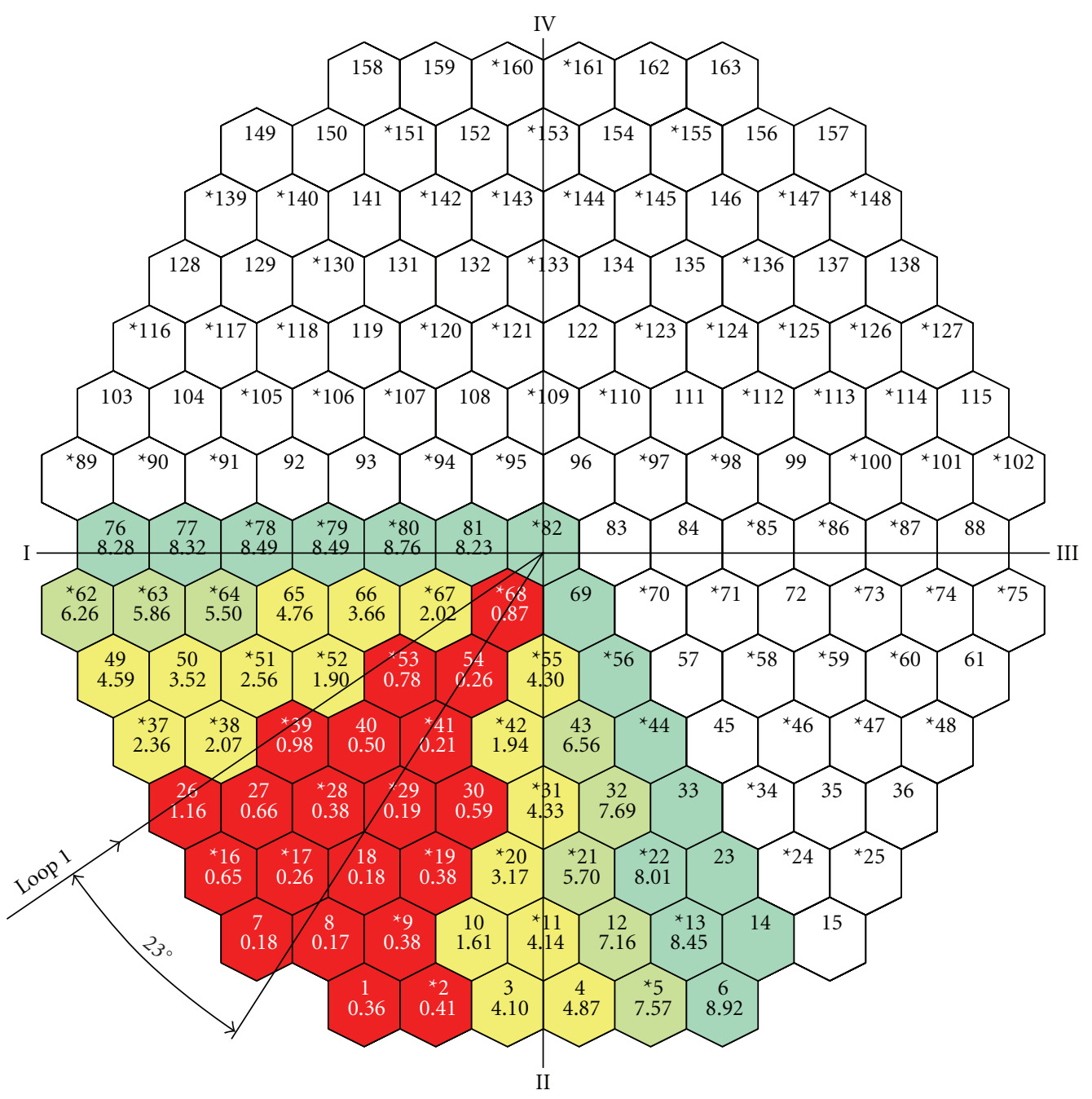

FIgURE 7: CATHARE 24-sector vessel model: angular turn of the loop no. 1 flow centre.

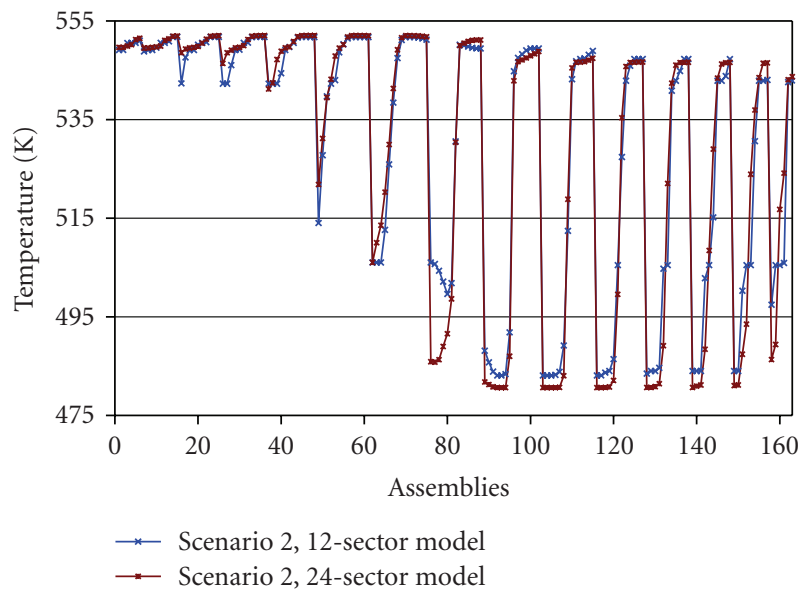

FIGURE 8: Snapshot for MSLB Scenario 2 at highest return to power: assembly by assembly core inlet temperatures for different angular meshes. 


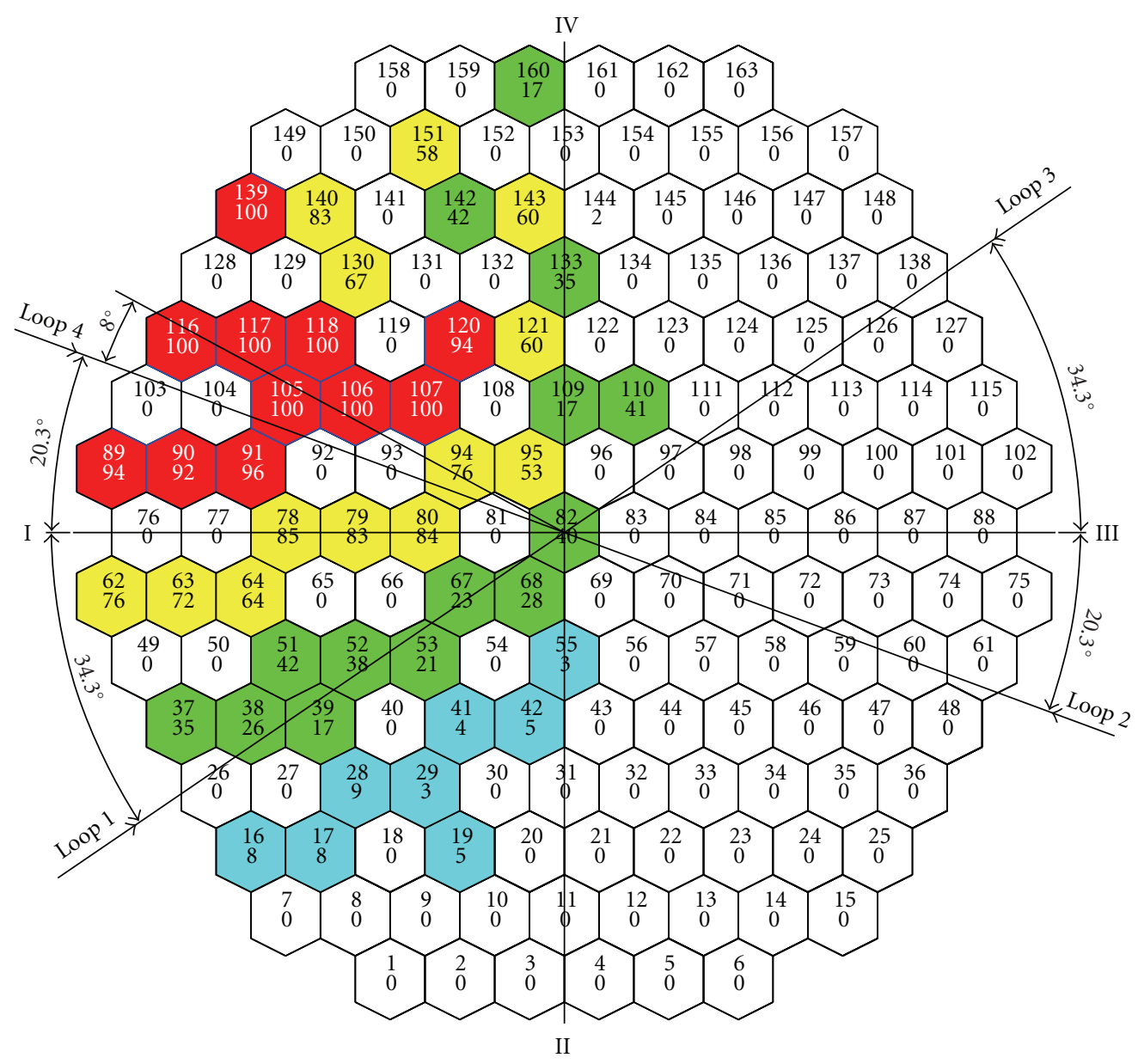

FIGURE 9: Kozloduy-6 vessel mixing experiment: assembly outlet data for loop-to-assembly mixing coefficients, and zone of minimal mixing and angular turn of the flow centre for loop no. 4.

the diffuser, as well as in the annular zones of the upper plenum and the outlet ring. Vertical junctions were used to a limited extent, with small relative flow area and in the lower and upper plenums only. Plant data from [1] were used to validate the multi-1D vessel mixing model.

The assembly by assembly temperature and flow distributions at the core inlet were obtained from the corresponding channel parameters through an appropriate mapping scheme. The temperature at the boundary between two sectors was taken as the weighted average of the two sector temperatures. This yields 88 inlet temperatures for the 12sector model and 154 ones for the 24 -sector model.

\section{Results}

5.1. Simulation of the Kozloduy-6 Flow Mixing Experiment. CATHARE multichannel-calculated results for the initial and final states are given in Tables 1 and 2. A good match of the reference states is achieved. In the discussion to follow we will consider the final asymmetric state.
Figure 4 shows the computed assembly-by-assembly core inlet temperatures in comparison with the plant-estimated data. Good overall agreement is displayed, with maximum deviations within a few K. Figure 5 illustrates the experimentally observed angular turn of the loop flow centre. In the present study the loop flow centre is defined as the centre line of the zone of minimal mixing. This zone is formed of assemblies where the temperature difference between the disturbed cold leg and each assembly inlet is $\leq 1.2 \mathrm{~K}$. Figures 6 and 7 show the computed angular turn of loop no. 1 flow. The results agree well with the plant data.

The code-to-experiment comparison illustrates the effects of azimuthal mesh refinement on the prediction of assembly inlet temperatures and the angular turn of the loop flow centres as well as the vessel outlet temperatures. Although radial refinement is not considered in this study, the results are quite reasonable due to the use of appropriate mapping schemes at the core inlet. The results show that for 16 or more azimuth meshes the computed angular shift of the loop flow centre with respect to the loop axis is in 


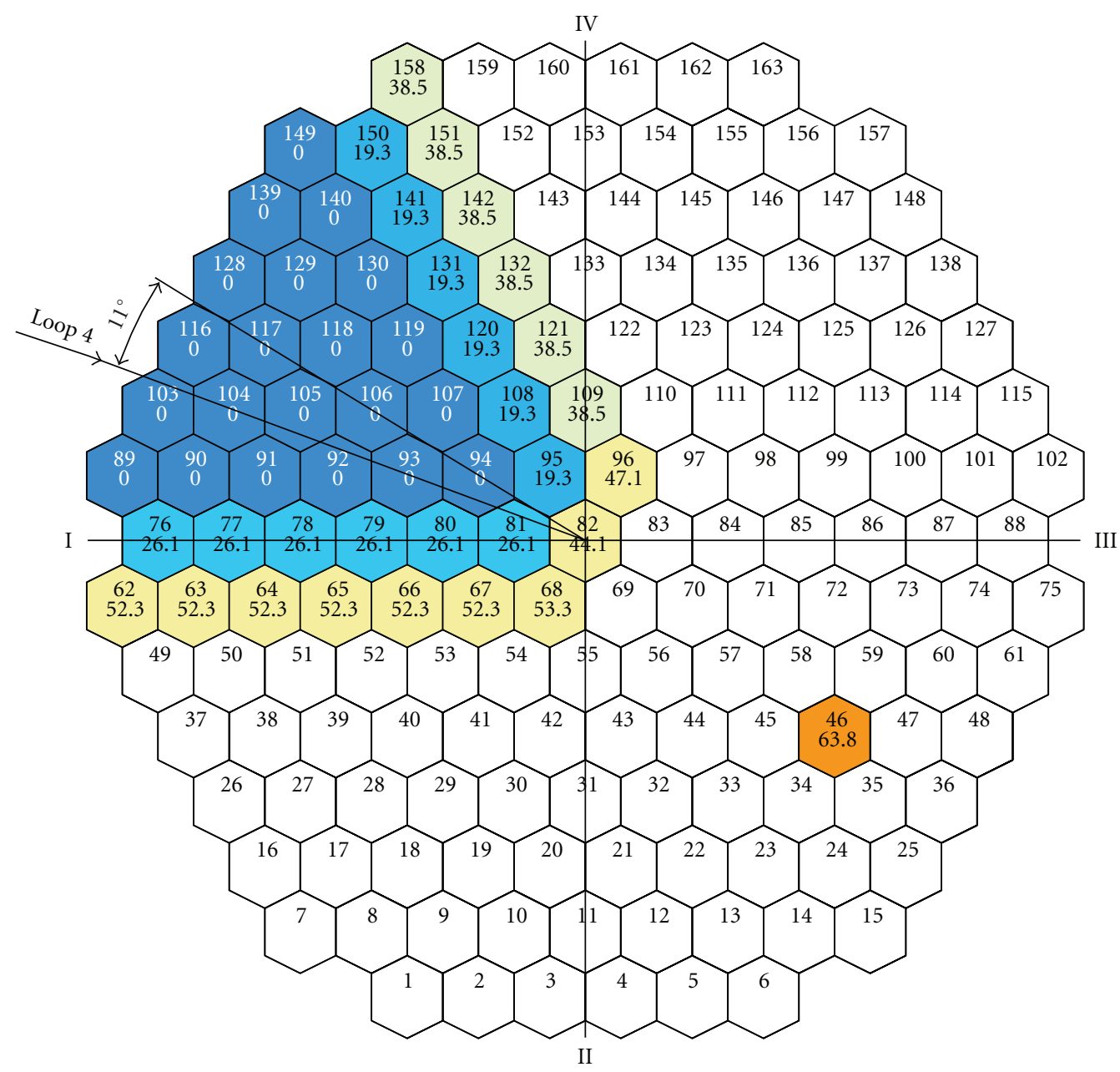

FIGURE 10: MSLB Scenario 2 with stuck rods no. 117 and no. 140: CATHARE 12-sector calculated angular turn of loop no. 4 flow centre.

TABLe 2: Final state.

\begin{tabular}{|c|c|c|c|c|c|}
\hline Parameter & Plant data & Cathare 12 sectors & Cathare16 sectors & Cathare 24 sectors & Uncertainty \\
\hline Core power, MW & 286 & 286 & 286 & 286 & \pm 60 \\
\hline Pressure above the core, $\mathrm{MPa}$ & 15.593 & 15.584 & 15.585 & 15.585 & \pm 0.3 \\
\hline Cold leg no. 1 coolant temp, K & 555.35 & $555.35(\mathrm{BC})$ & $555.35(\mathrm{BC})$ & $555.35(\mathrm{BC})$ & \pm 1.5 \\
\hline Cold leg no. 2 coolant temp, K & 543.05 & $543.05(\mathrm{BC})$ & $543.05(\mathrm{BC})$ & $543.05(\mathrm{BC})$ & \pm 1.5 \\
\hline Cold leg no. 3 coolant temp, K & 542.15 & $542.15(\mathrm{BC})$ & $542.15(\mathrm{BC})$ & $542.15(\mathrm{BC})$ & \pm 1.5 \\
\hline Cold leg no. 4 coolant temp, K & 542.35 & $542.35(\mathrm{BC})$ & $542.35(\mathrm{BC})$ & $542.35(\mathrm{BC})$ & \pm 1.5 \\
\hline Mass flow rate $1, \mathrm{~kg} / \mathrm{s}$ & 4566 & 4569.8 & 4567.4 & 4567.5 & \pm 200 \\
\hline Mass flow rate $2, \mathrm{~kg} / \mathrm{s}$ & 4676 & 4677.0 & 4676.2 & 4676.2 & \pm 200 \\
\hline Mass flow rate $3, \mathrm{~kg} / \mathrm{s}$ & 4669 & 4668.2 & 4668.2 & 4668.2 & \pm 200 \\
\hline Mass flow rate $4, \mathrm{~kg} / \mathrm{s}$ & 4819 & 4818.2 & 4818.2 & 4818.2 & \pm 200 \\
\hline Reactor mass flow rate, $\mathrm{kg} / \mathrm{s}$ & 18730 & 18733.2 & 18729.9 & 18730 & \pm 800 \\
\hline Hot leg no. 1 coolant temp, $\mathrm{K}$ & 554.85 & 554.49 & 554.64 & 555.24 & \pm 1.5 \\
\hline Hot leg no. 2 coolant temp, $\mathrm{K}$ & 548.15 & 548.19 & 548.55 & 547.54 & \pm 1.5 \\
\hline Hot leg no. 3 coolant temp, $\mathrm{K}$ & 545.75 & 545.54 & 545.53 & 545.48 & \pm 1.5 \\
\hline Hot leg no. 4 coolant temp, $\mathrm{K}$ & 546.45 & 546.92 & 546.44 & 546.89 & \pm 1.5 \\
\hline Reactor pressure drop, $\mathrm{MPa}$ & 0.419 & 0.410 & 0.411 & 0.411 & \pm 0.043 \\
\hline
\end{tabular}




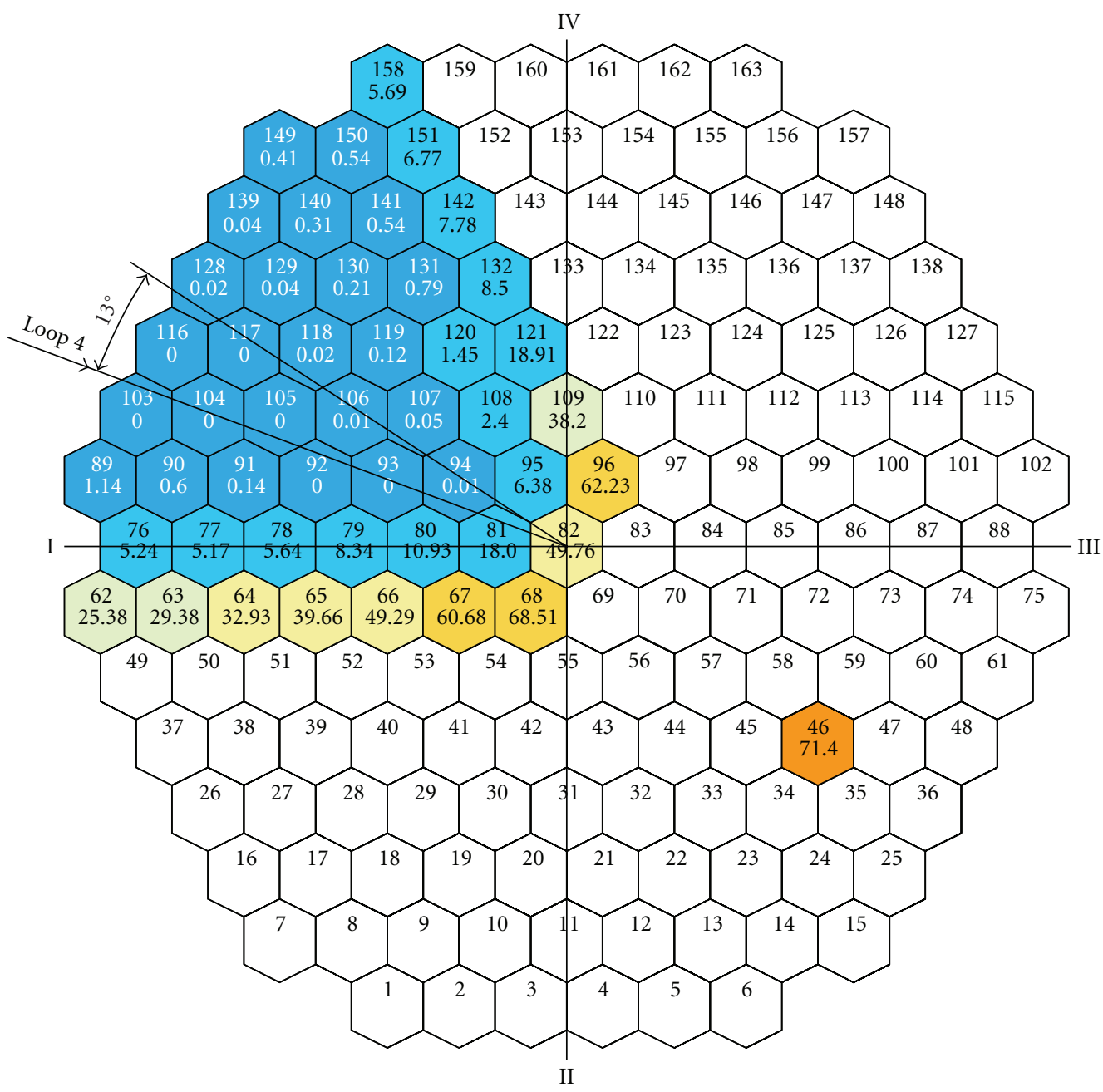

FIGURE 11: MSLB Scenario 2 with stuck rods no. 117 and no. 140. CATHARE 24-sector calculated angular turn of loop no. 4 flow centre.

good agreement with the plant data. The maximal deviations between the computed assembly inlet temperatures and plant estimated data are $3.41 \mathrm{~K}$ for 24 azimuth sectors, $4.88 \mathrm{~K}$ for 16 sectors, and $5.01 \mathrm{~K}$ for the 12 -sector model. The average in modulus deviations are $0.94 \mathrm{~K}$ for 24 sectors, $0.92 \mathrm{~K}$ for 16 sectors and $0.92 \mathrm{~K}$ for 12 sectors.

\subsection{MSLB Mixing Calculations. Figure 8 shows a} CATHARE-CATHARE comparison of assembly inlet temperatures for Scenario 2 at the highest return to power illustrating the effect of angular mesh refinement.

Plant-estimated data for the angular turn of loop no. 4 flow [1] shown in Figure 9 can be used for qualitative comparison of the computed angles, displayed in Figures 10 and 11. The angular turn in Figure 9 is estimated in terms of loop-to-assembly outlet mixing coefficients Cnk $(\%)$, defined as the ratio of flow from loop $n$ into assembly $k$ to the total flow through assembly $k$. The zone of minimal mixing is formed by assemblies with $90 \%<C_{n k}<$ $100 \%$ (approximately equivalent to $\delta T_{n k}<1.2 \mathrm{~K}$ ). Reasonable agreement is observed when using validated multichannel models with cross-flow.

The results in Figures 10 and 11 show that the validated multichannel vessel mixing models are applicable to the analysis of the initial phase of MSLB transients. The maximal errors can be reduced by further azimuthal and radial mesh refinement. The performance of the vessel mixing models in case of flow reversal in the affected loop is subject of a separate study.

\section{Conclusions}

Computationally efficient multichannel vessel models with cross flow can produce reasonable flow mixing results for asymmetric transients with sector formation.

A minimum of $12-16$ azimuth sectors is required for acceptable accuracy such that the maximal errors in assembly inlet temperatures are in the order of a few K.

The results are of practical value for current safety analyses with system codes because of the strong impact of vessel mixing on the $3 \mathrm{D}$ core dynamics. 


\section{Acknowledgment}

This study was carried out by using CATHARE2 V2.5 developed by CEA, EDF, AREVA NP, and IRSN.

\section{References}

[1] N. P. Kolev, S. Aniel, E. Royer, U. Bieder, D. Popov, and Ts. Topalov, "VVER-1000 Coolant Transient Benchmark (V1000CT-2): Specifications of the VVER-1000 vessel mixing problems," OECD NEA/NSC/DOC(2004)6; Rev.1, 2006, http://www.nea.fr/html/science/egrsltb/v1000ct/index.html.

[2] N. P. Kolev, et al., "VVER-1000 Coolant Transient Benchmark (V1000CT-2 Vol.2): Specifications of the VVER1000 MSLB problem,” OECD NEA/NSC/DOC(2006), http://www.nea.fr/html/science/egrsltb/v1000ct/index.html.

[3] CATHARE 2.5 Manuals, CEA Grenoble, 2006.

[4] N. P. Kolev, N. Petrov, L. Sabotinov, S. Nikonov, and J. Donov, "Validation cases of CATHARE2 for VVER-1000 main steam line break analysis," Journal of Power and Energy Systems, vol. 2, no. 2, pp. 512-521, 2008.

[5] I. Spasov, J. Donov, S. Stoyanov, and N. P. Kolev, "CATHARE multi-channel calculation of the coolant mixing in VVER1000," Annual Report, TU-Sofia, 2008.

[6] N. P. Kolev, I. Spasov, and E. Royer, "VVER-1000 Coolant Transient Benchmark (V1000CT-2 Vol.3): Summary results of Exercise 1 on Vessel Mixing Simulation" NEA/NSC/ DOC(2009)," http://www.nea.fr/html/science/egrsltb/v1000ct/index.html. 

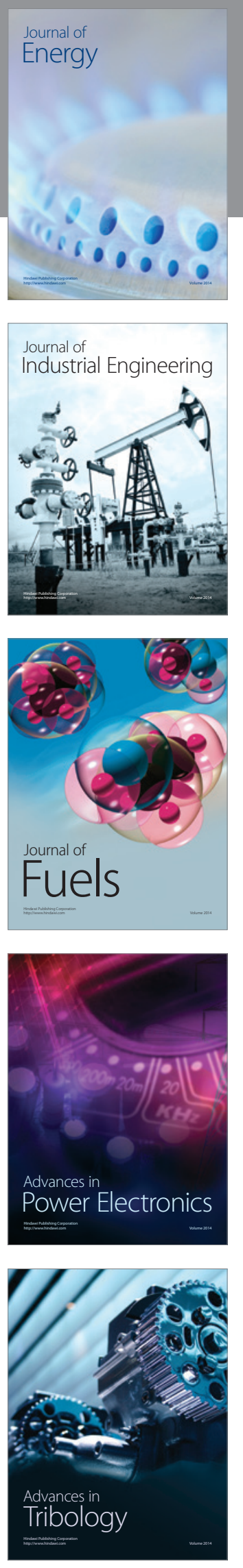
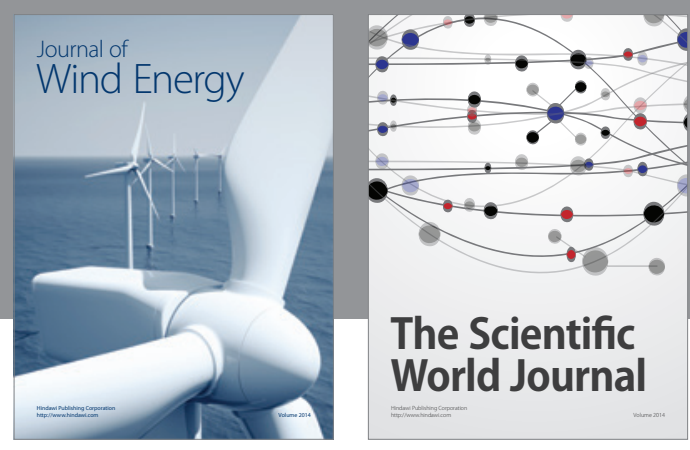

The Scientific World Journal

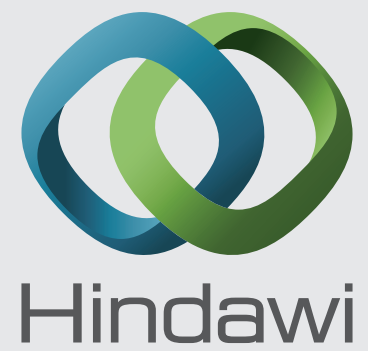

Submit your manuscripts at http://www.hindawi.com
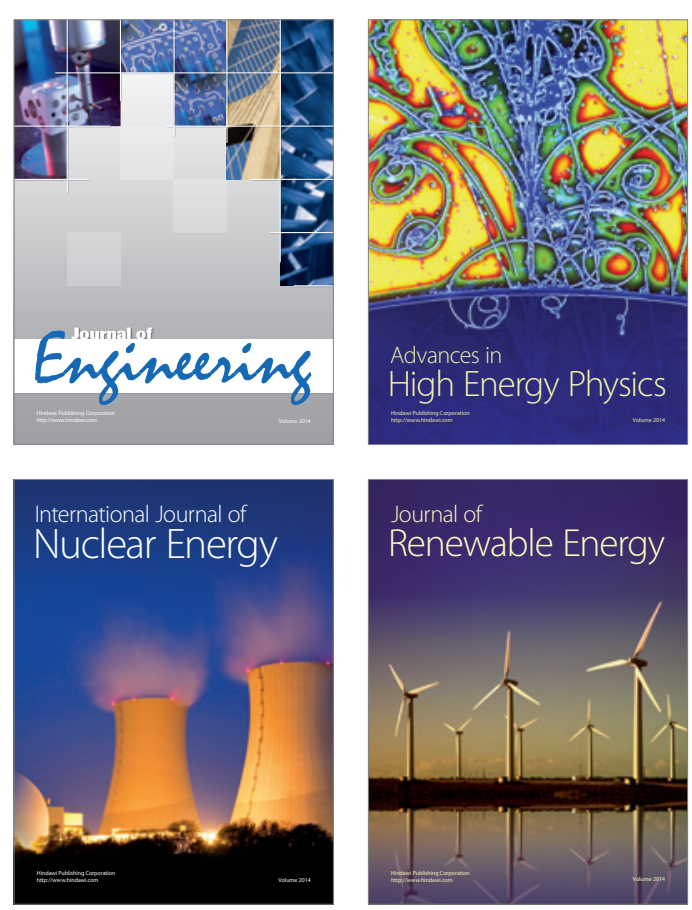

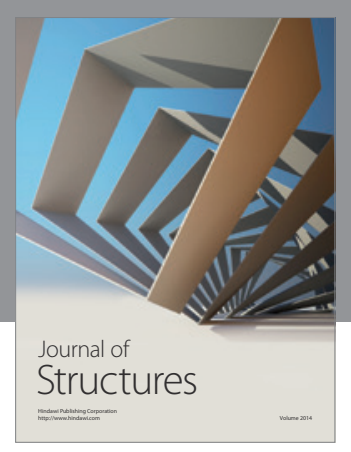

Rotating
Mechinery
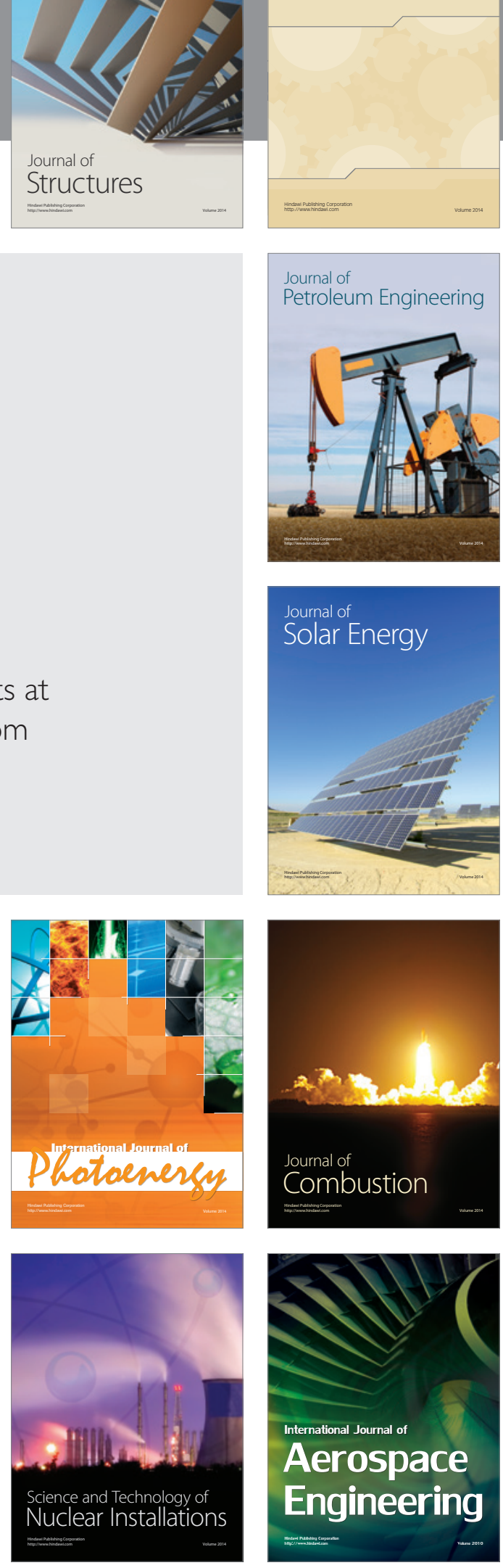